\title{
Do People with Borderline Personality Disorder Complicated by Antisocial Personality Disorder Benefit from the STEPPS Treatment Program?
}

\author{
Donald W. Black, MD, Fatma Simsek-Duran, MD, PhD, Nancee Blum, MSW, Brett \\ McCormick, MA, and Jeff Allen, PhD \\ Department of Psychiatry, University of lowa Roy J. and Lucille A. Carver College of Medicine, \\ lowa City, IA 52242
}

\begin{abstract}
Systems Training for Emotional Predictability and Problem Solving (STEPPS) is a group treatment for persons with borderline personality disorder (BPD). We describe results from two data sets on outcome in persons who participated in STEPPS with BPD alone or BPD plus antisocial personality disorder (ASPD). In Study 1, we examined the effect of comorbid ASPD on outcome in 65 persons with BPD who participated in a randomized controlled trial at an academic medical center. In Study 2, we examined the effect of comorbid ASPD on outcome in 64 offenders with BPD who participated in STEPPS in correctional settings. All subjects were assessed for the presence of BPD and ASPD. In Study 1, subjects with ASPD experienced greater improvement in BPD symptoms, impulsiveness, and global symptoms. In Study 2, offenders with ASPD experienced greater improvement in positive and negative behaviors and positive affectivity. We conclude that persons with BPD plus ASPD benefit from STEPPS in community and correctional settings. The findings suggest that persons with BPD plus ASPD show greater improvement in some domains than persons with BPD only. People with ASPD should not be automatically excluded from participation in the program.
\end{abstract}

\section{Keywords}

Borderline personality disorder; antisocial personality disorder; STEPPS; randomized controlled trials (RCTs)

\begin{abstract}
Borderline personality disorder (BPD) is characterized by a pervasive pattern of emotional instability, impulsivity, and disturbed relationships (Lieb et al., 2004). Psychotherapy has been the most frequently studied treatment and many programs are now evidence-based including Systems Training for Emotional Predictability and Problem Solving (STEPPS) (NICE, 2009). Briefly, STEPPS was developed at the University of Iowa for ambulatory patients with BPD and has been shown to be effective in controlled and uncontrolled studies (Blum et al., 2008; Bos et al., 2010; Freije et al., 2002; Harvey et al., 2010). The program has been shown to reduce borderline psychopathology, depressive symptoms, and negative
\end{abstract}

Correspondence: Dr. Black, 2-126B MEB/Psychiatry Research, University of Iowa Carver College of Medicine, Iowa City, IA 52242, Phone: 319-353-4431, fax: 319-353-3003, donald-black@uiowa.edu. 
affectivity. In some studies, STEPPS also appears to reduce suicidality and, in prison, disciplinary infractions (Black et al., 2013; Harvey et al., 2010).

BPD is common in the general population with a prevalence between 1\%-6\% (Grant et al., 2008; Lenzenweger et al., 2007), but is also prevalent in prisons with rates as high as $30 \%$ of incarcerated offenders (Black et al., 2007; de Ruiter \& Treatment, 2006; Jordan et al., 1996; Zlotnick, 1999). Research shows that there is great overlap of BPD with antisocial personality disorder (ASPD) in these settings. For example, in one study $57 \%$ of offenders with BPD also met criteria for ASPD (Black et al., 2007). BPD is problematic in prison settings and contributes to behavioral and management problems (Warren et al., 2002).

Despite the high prevalence of BPD in corrections, few formal treatment programs have been developed or implemented in these settings (Berzins \& Trestman, 2004; Black et al., 2013; McCann et al., 2000). We have been working with the Iowa Department of Corrections (IDOC) since 2005 to implement and provide ongoing monitoring of the STEPPS program in both prison and community corrections settings (Black et al., 2008; 2013). We have reported data which show the program produces clinical benefit and is well accepted by offenders and corrections staff (Black et al., 2008; 2013).

An important question is whether people with BPD plus comorbid antisocial personality disorder (ASPD) benefit from STEPPS. While the disorders frequently overlap, there has been little effort to examine the influence of ASPD on treatment outcome of persons with BPD. Unlike BPD wherein treatment has been actively investigated, the same is not true for ASPD. There are currently no programs designed specifically to treat ASPD and many mental health professionals believe the disorder is untreatable (Black, 2013). Therapeutic nihilism is unwarranted because the question of its treatment has been largely ignored and the issue is understudied (NICE, 2009).

We had an opportunity to examine the issue of treatment response in persons with BPD plus ASPD and now present data from two sources: 1) a randomized controlled trial (RCT) of STEPPS conducted at an academic medical center; and 2) the naturalistic experience with STEPPS conducted in correctional settings. Based on our experience, we expected that BPD patients with ASPD and those with BPD alone would experience similar levels of clinical improvement in both settings.

\section{Methods}

Study 1 involves a reanalysis of data collected in the conduct of an RCT at the University of Iowa (Blum et al., 2008) and has not been previously published. Subjects were 18 years or older and met DSM-IV criteria (American Psychiatric Association, 2000) for BPD. The diagnosis was confirmed using the Structured Interview for DSM-IV Personality (SIDP-IV; Pfohl et al., 1997). Subjects gave written informed consent according to procedures approved by the University of Iowa Institutional Review Board. They could not have a psychotic, cognitive, or primary neurological disorder, or current (past month) substance abuse or dependence (except tobacco dependence), or have participated in a STEPPS program. 
Axis I and II disorders were assessed with the Structured Clinical Interview for DSM-IV (SCID; Spitzer et al., 1994) and the SIDP-IV (Pfohl et al., 1997). Outcome measures included the Zanarini Rating Scale for Borderline Personality Disorder (ZAN-BPD; Zanarini, 2003), the Borderline Evaluation of Severity Over Time (BEST; Pfohl et al., 2009), the Symptom Checklist-90-R (SCL-90-R; Derogatis, 1983), the Social Adjustment Scale (SAS; Weissman \& Bothwell, 1976), the Clinical Global Impressions (CGI) severity scale (CGI; Guy, 1976), the Barratt Impulsiveness Scale (BIS; Barratt, 1959), the Global Assessment Scale (GAS; Endicott et al., 1976), the Beck Depression Inventory (BDI; Beck, 1978), and the Positive and Negative Affect Schedule (PANAS; Watson \& Clark, 1994).

Subjects were randomly assigned to STEPPS plus treatment as usual or to treatment as usual alone. All subjects were encouraged to continue their usual care including individual psychotherapy, medication, and case management. Subjects assigned to treatment as usual alone were not allowed to attend a STEPPS program until they completed the 20 week study. Subjects were followed for one year after completing the 20 week study period.

Study 2 involved the reanalysis of data collected by the Iowa Department of Corrections (IDOC) during the routine conduct of STEPPS in prison and community corrections settings (Black et al., 2013). The data reported herein have not been previously published. Participation in STEPPS is considered part of an offender's mental health care within the IDOC and data are routinely collected for the purpose of program evaluation. For that reason, data collection is not considered research and informed consent is not obtained from offenders. University of Iowa Institutional Review Board permission was granted for a secondary data analysis. Deidentified data were made available to the research team to preserve offender confidentiality. Study 2 did not include a control group for testing the effect of STEPPS. Because the present study focuses only on those who received STEPPS, and the comparison of interest is individuals with BPD alone versus those with BPD plus ASPD, results from the two studies can be compared and do not require a control group.

Offenders had to meet DSM-IV criteria for BPD. Modules on BPD and ASPD from the SIDP-IV were administered to assess the presence of BPD and ASPD. They were enrolled in STEPPS groups at one of three Iowa prisons or in community corrections in Cedar Rapids, IA. Violent offenders, those requiring special programming (e.g., close supervision, segregation, seclusion), and those requiring maximum security placement are not included because of security concerns. Data on the experience of the first 77 offenders has already been published (Black et al., 2008; 2013). (The number in the current analysis is less than 77 because not all offenders were assessed for ASPD.) Self-report assessments included the BEST, the BDI, and the PANAS.

\section{Statistical Analysis}

For both studies, BPD subjects with ASPD were compared to those without ASPD on social, demographic, and clinical variables measured at baseline. Baseline variables used in both studies included age, sex, race/ethnicity, marital status, educational level, employment status, and prior psychiatric hospitalization. Additional variables compared for Study 1 included prior suicide attempts, prior acts of self-harm, number of psychotropic medications, current major depressive disorder, number of lifetime Axis I and II disorders, and number of BPD 
criteria met. Additional variables compared for Study 2 included total number of medications, lifetime Axis I disorders, and whether their conviction was for a violent act. The Pearson Chi-square test (or Fisher's Exact test, where appropriate) was used to compare the groups on categorical variables and the Mann-Whitney test was used to compare the groups on dimensional variables. Variables with significant differences would suggest underlying differences between subjects with and without ASPD that may need to be controlled in the analysis of STEPPS treatment outcomes.

In Study 1, subjects were assessed at baseline and regular intervals during the treatment period (weeks $4,8,12,16$, and 20). We assessed treatment response with six rating scales: the CGI, ZAN-BPD, BEST, GAS, BIS, and BDI. Using these scales, we measured improvement in four domains: overall BPD severity (ZAN-BPD, BEST), global severity (CGI, GAS), depressive symptoms (BDI), and impulsivity (BIS). Study 2 assessed subjects at the same time points (baseline, weeks 4, 8, 12, 16, and 20) using a subset of the scales used in study 1 (BEST, PANAS, BDI).

For both studies, level of treatment response was defined as the improvement relative to the baseline assessment. A linear mixed-effects model was used and each subject's trajectory of scores from baseline to week 20 was summarized with a subject-specific intercept and slope. For Study 1, sex was used as a covariate for both intercept and slope. We tested for differences in mean slope among subjects with BPD only and subjects with BPD and ASPD. Effect sizes were computed as the difference in mean improvement from baseline to week 20, divided by the standard deviation at baseline. Analyses were carried out using SAS (2011) and all tests were performed using a two-sided significance level of 0.05 .

\section{Results}

In Study 1, 65 subjects who were randomized to STEPPS plus treatment as usual received the allocated intervention (STEPPS) and were used in the analysis. Among these subjects, 49 were diagnosed with BPD alone and 16 were diagnosed with BPD plus ASPD. The two groups were similar on age (range 19 to 56 years, mean $=31.7, \mathrm{SD}=8.4$ ), race/ethnicity $(95 \%$ Caucasian), marital status, educational level, employment status, suicide and self-harm incidents, and prior psychiatric hospitalization (Table 1). Group differences were observed for sex ( $88 \%$ female for BPD alone, $56 \%$ female for BPD plus ASPD), number of lifetime SCID disorders (mean of 7.1 for subjects with BPD alone, mean of 10.3 for subjects with BPD plus ASPD) and number of SIDP-IV disorders (mean of 2.7 for subjects with BPD alone, mean of 4.5 for subjects with BPD plus ASPD). Sex was used as a covariate in the comparison of STEPPS treatment outcomes. In the study 1 sample, the mean (SD) number of STEPPS sessions attended was 13.1 (5.3) for subjects with BPD only and 12.4 (5.4) for subjects with BPD plus ASPD. The mean number of sessions attended was also similar for men (14.3) and women (12.6).

In Study 2, 64 subjects participated in STEPPS in correctional settings (55 in prison, 9 in community settings). Among these subjects, 20 were diagnosed with BPD alone and 44 were diagnosed with BPD plus ASPD. The two groups were similar on age (range 19 to 50 years, mean $=30.9, \mathrm{SD}=8.8)$, sex ( $78 \%$ female), race/ethnicity ( $89 \%$ Caucasian), marital 
status, educational level (27\% less than high school), employment status, prior psychiatric hospitalization, number of medications, and lifetime mental health disorders (Table 2). In the study 2 sample, 7 subjects (11\%) dropped out after the baseline assessment, $9(14 \%)$ dropped out after week 4, 7 (11\%) dropped out after weeks 8 and 12, 1 dropped out after week 16, and $33(52 \%)$ completed all 20 sessions. In nearly all cases, drop outs occurred because of transfers to another institution or release from prison. Completion rates did not vary significantly by ASPD status.

For Study 1, improvements in BPD-related symptoms, mood, impulsivity, and affectivity were assessed by comparing baseline scores to those in subsequent weeks using a linear mixed-effects model (Table 3), adjusted for sex. The comparison of interest was the mean slope for subjects with BPD randomized to STEPPS plus treatment as usual versus the mean slope for subjects with BPD randomized to treatment as usual only (Blum et al., 2008). The comparison of interest in this study is the mean slope for subjects with BPD plus ASPD versus the mean slope for subjects with BPD alone. Significant differences in slope were observed for ZAN-BPD (total score and impulsivity subscale) and BIS score. The effect size (ES) measures the difference in the mean slopes for the two groups (BPD plus ASPD group mean slope - BPD alone group mean slope). The direction of the effect sizes for the ZANBPD scores and BIS score were negative, suggesting a greater level of improvement (reduction in severity) for subjects with BPD plus ASPD, compared to those with BPD alone. The largest effect sizes were observed for BIS score (ES=-0.88) and ZAN-BPD impulsivity subscale $(E S=-0.79)$. Figure 1 plots ZAN-BPD total scores at baseline, week 8 , and week 20 for the two groups. (Note that in Study 1, ZAN-BPD data was not collected at weeks 4, 12, and 16). The mean scores in Figure 1 were estimated using a repeated measures ANOVA model, allowing for nonlinearity in response trajectories. Figure 1 shows that both groups experienced improvement, and that subjects with BPD plus ASPD experienced more improvement than subjects with BPD alone.

For Study 2, improvements in BPD-related symptoms, mood, and affectivity were assessed by comparing baseline scores to those in subsequent weeks using the linear mixed-effects model (Table 4). Significant differences in slope were observed for BEST scores, with the exception of the Thoughts/Feelings subscale, and the PANAS Positive Affectivity scale. The direction of the effect sizes for the BEST scores and PANAS positive affectivity score suggest a greater level of improvement for subjects with BPD plus ASPD, compared to those with BPD alone. The largest effect sizes were observed for BEST Positive Behaviors $(\mathrm{ES}=1.22)$ and PANAS Positive Affectivity (ES=0.89). Figure 2 plots BEST total scores at baseline and weeks 4, 8, 12,16, and 20. The mean scores in Figure 2 were estimated using a repeated measures ANOVA model, allowing for nonlinearity in response trajectories. Figure 2 shows that both groups experienced improvement in BEST total scores, and that subjects with BPD plus ASPD experienced more improvement than subjects with BPD alone.

\section{Discussion}

Both studies show that persons with BPD plus comorbid ASPD have clinically meaningful improvement with STEPPS to a magnitude similar to (or greater than) that seen in persons with BPD alone. Participants in the RCT at the University of Iowa and offenders treated in 
the IDOC experienced similar improvements in BPD-related symptoms, mood, and negative affectivity. Thus, the benefit of STEPPS appears to extend beyond those with BPD alone and is clearly beneficial to those with BPD complicated by ASPD.

The results are important. Because of the broad overlap of the borderline and antisocial syndromes, many people have likely been excluded from participating in an evidence-based treatment program. One fear that prevents their participation is that individuals with antisocial traits will either act-out and disrupt the group process, or will misbehave in some other way (e.g., make threats toward participants or therapists). While these concerns have some validity, in our own work in both university and correctional settings, they occur infrequently and can be dealt with on a case-by-case basis. In fact, in neither setting was any antisocial subject removed from a STEPPS group. There are currently no standard treatments for ASPD, but one strategy may be to encourage antisocial patients with concurrent BPD to enroll in STEPPS. Whether these positive results would apply to other evidence-based programs is unknown since the issue has not been addressed (Bateman \& Fonagy, 1999; Clarkin et al., 2007; Giesen-Bloo et al., 2006; Linehan et al., 2006).

It is not clear why the borderline patient with comorbid ASPD would have a better response to STEPPS than the person with BPD alone. In fact, the results are counterintuitive because ASPD has long been associated with poor treatment response (Mather, 1987; Woody et al., 1985). The disorder itself has been deemed untreatable, though this conclusion is based mainly on clinical surmise and not empirical data (NICE, 2009). If fact, only one RCT has been conducted worldwide in persons with ASPD. The study of 52 men with ASPD tested cognitive behavioral therapy (CBT) which was not superior to "usual care." Despite these findings, Davidson et al. (2010) reported that, "The view from the ground ... was that doing [CBT] was helpful in reducing antisocial behaviours and changing thinking" (p. 94). While this, and other early data, suggest that CBT can be helpful, only larger, and longer term studies can show its true effectiveness. Other investigators may now wish to revisit the issue of ASPD treatability because it is clear that - at least in the context of BPD - its presence does not interfere with treatment success in the STEPPS program.

The presence of ASPD was generally associated with greater symptom levels in both community and correctional settings. This could indicate that the subjects with BPD plus ASPD groups simply had more to gain from treatment than the others. Through the phenomenon of "regression to the mean," subjects at the end of a frequency distribution have the farthest to move.

Depression was prevalent in both samples $-51 \%$ among participants in the RCT and $80 \%$ among offenders treated at the IDOC. The present study did not examine STEPPS treatment response by depression status. Previously, we reported that depression was not associated with BPD symptom improvement among individuals in the STEPPS RCT (Black et al., 2009) nor among offenders treated at the IDOC (Black et al., 2013). Among participants in the RCT who received the STEPPS treatment, the mean number of STEPPS sessions attended was the same for individuals with and without major depression (12.9), suggesting that major depression does not have a large effect on STEPPS engagement. 
Because ASPD is more prevalent among men, there is a potential that the BPD versus BPD plus ASPD comparison is confounded by sex. For Study 1, sex was used as a covariate because ASPD was significantly more common in men. For Study 2, the two groups were similar on sex, with 78\% overall female. Previously, we reported that sex was not associated with ZAN-BPD improvement among individuals in the STEPPS RCT (Black et al., 2009) nor with BEST improvement among offenders treated at the IDOC (Black et al., 2013). Among women with BPD, ASPD was much more prevalent in the correctional setting (70\%) compared to the clinical setting (17\%). Among men with BPD, rates of ASPD were similar in the two settings.

There are several limitations to acknowledge. Data were collected during the conduct of STEPPS in widely different settings and the program may not have been delivered in a comparable way. Fidelity was measured in the RCT, but was generally not measured in the correctional system. While the three evaluations used in correctional settings were used in the RCT, the assessment of offenders is otherwise limited and important findings may have been missed. Because violent offenders, those requiring special programming (e.g., close supervision, segregation, seclusion), and those requiring maximum security were not included, the findings cannot be generalized to these groups. The racial background of subjects in both studies was mostly Caucasian which reduces the generalizability of the data to minority groups.

Last, STEPPS is designed to treat BPD, not ASPD, and for that reason we did not include measures to assess the impact of the program on comorbid ASPD. Thus, we cannot comment on whether the program would be helpful in treating ASPD. Despite these concerns, the fact that both data sets yield remarkably similar findings strengthens our conclusion that STEPPS delivers comparable benefit to people with BPD alone and those with BPD plus ASPD. We believe there is no reason to exclude individuals with BPD with comorbid ASPD from participation in the STEPPS program in the absence of a strong rationale, such as a history of violence toward women. Other programs have been silent on the issue of comorbid ASPD, and so it is unknown whether these findings would apply to other programs such as dialectical behavior therapy. STEPPS may have a special role in correctional systems where there is a high likelihood of an offender having both borderline and antisocial syndromes.

\section{Acknowledgements}

The research was supported through grants from the National Institute of Mental Health, Bethesda, MD (R01MH63746) and the Nellie Ball Trust (MidWestOne Bank, Iowa City, IA). Dr. Black receives royalties from American Psychiatric Publishing, Oxford University Press, and UpToDate. Ms. Blum receives royalties from Level One Publishing, LLC; American Psychiatric Publishing; Psychiatry Verlag; STEPPS Italia; and Sussex Partnership NHS Foundation Trust. for sales of the STEPPS CD-ROM. Drs. Simsek-Duran and Allen, and Mr. McCormick report no conflicts. We thank Dr. Harbans Deol at the Iowa Department of Corrections for supporting the implementation of STEPPS and for facilitating data collection.

\section{References}

American Psychiatric Association. Diagnostic and statistical manual of mental disorders. 4th ed., text rev.. Washington, DC: 2000. 
Barratt E. Anxiety and impulsiveness related to psychomotor efficiency. Perceptual Motor Skills. 1959; 9:191-198.

Bateman A, Fonagy P. Effectiveness of partial hospitalization in the treatment of borderline personality disorder: a randomized controlled trial. American Journal of psychiatry. 1999; 156(10):1563-1569. [PubMed: 10518167]

Berzins LG, Trestman RL. The development and implementation of dialectical behavior therapy in forensic settings. International Journal of Forensic Mental Health. 2004; 3(1):93-103.

Black, DW. Bad Boys, Bad Men: Confronting Antisocial Personality Disorder (sociopathy). Oxford University Press; 2013.

Black DW, Blum N, McCormick B, Allen J. STEPPS group treatment program for borderline offenders. Journal of Nervous and Mental DIsease. 2013; 201:124-129. [PubMed: 23364121]

Black DW, Blum N, Pfohl B, Hale N. Suicidal behavior in borderline personality disorder: prevalence, risk factors, prediction, and prevention. Journal of Personality Disorders. 2004; 18(3):226-239. [PubMed: 15237043]

Black DW, Blum N, Pfohl B, St. John D, McCormick B, Allen J. Predictors of response to Systems Training to Emotional Predictability and Problem Solving (STEPPS) for borderline personality disorder: an exploratory study. Acta Psychiatrica Scandinavica. 2009; 120:53-61. [PubMed: 19183126]

Black DW, Blum N, Eichinger L, McCormick B, Allen J, Sieleni B. STEPPS: Systems Training for Emotional Predictability and Problem Solving in women offenders with borderline personality disorder in prison-A pilot study. CNS spectrums. 2008; 13(10):881-886. [PubMed: 18955943]

Black DW, Gunter T, Allen J, Blum N, Arndt S, Wenman G, Sieleni B. Borderline personality disorder in male and female offenders newly committed to prison. Comprehensive Psychiatry. 2007; 48(5): 400-405. [PubMed: 17707246]

Blum N, St. John D, Pfohl B, Stuart S, McCormick B, Allen J, Black DW. Systems Training for Emotional Predictability and Problem Solving (STEPPS) for outpatients with borderline personality disorder: a randomized controlled trial and 1-year follow-up. American Journal of Psychiatry. 2008; 165(4):468-478. [PubMed: 18281407]

Bos EH, van Wel EB, Appelo MT, Verbraak MJ. A randomized controlled trial of a Dutch version of systems training for emotional predictability and problem solving for borderline personality disorder. The Journal of nervous and mental disease. 2010; 198(4):299-304. [PubMed: 20386260]

Bos EH, Van Wel EB, Appelo MT, Verbraak MJ. Effectiveness of Systems Training for Emotional Predictability and Problem Solving (STEPPS) for Borderline Personality Problems in a 'RealWorld'Sample: Moderation by Diagnosis or Severity?. Psychotherapy and Psychosomatics. 2011; 80(3):173-181. [PubMed: 21389754]

Clarkin JF, Levy KN, Lenzenweger MF, Kernberg OF. Evaluating three treatments for borderline personality disorder: a multiwave study. American Journal of Psychiatry. 2007; 164(6):922-928. [PubMed: 17541052]

Davidson K, Halford J, Kirkwood L, Newton-Howes G, Sharp M, Tata P. CBT for violent men with antisocial personality disorder. Reflections on the experience of carrying out therapy in MASCOT, a pilot randomized controlled trial. Personality and Mental Health. 2010; 4(2):86-95.

Derogatis, L,R. SCL-90-R Administration, Scoring, and Procedures Manual II. Clinical Psychometric Research; Towson, MD: 1983.

de Ruiter C, Trestman RL. Prevalence and treatment of personality disorders in Dutch forensic mental health services. Journal of the American Academy of Psychiatry and the Law. 2006; 35(1):92-97. [PubMed: 17389350]

Endicott J, Spitzer RL, Fleiss JL, Cohen J. The Global Assessment Scale: A procedure for measuring overall severity of psychiatric disturbance. Archives of General Psychiatry. 1976; 33:766-771. [PubMed: 938196]

Freije H, Dietz B, Appelo. M. Behandling van de borderline persoonlijk heidsstoornis met de VERS: de Vaardigheidstraining emotionele regulatiestoornis. Directive Therapies. 2002; 4:367-378.

Giesen-Bloo J, Van Dyck R, Spinhoven P, Van Tilburg W, Dirksen C, Van Asselt T, Arntz A. Outpatient psychotherapy for borderline personality disorder: randomized trial of schema-focused 
therapy vs transference-focused psychotherapy. Archives of General Psychiatry. 2006; 63(6):649_ 658. [PubMed: 16754838]

Grant BF, Chou SP, Goldstein RB, Huang B, Stinson FS, Saha TD, Ruan WJ. Prevalence, correlates, disability, and comorbidity of DSM-IV borderline personality disorder: results from the Wave 2 National Epidemiologic Survey on Alcohol and Related Conditions. Journal of Clinical Psychiatry. 2008; 69(4):533-545. [PubMed: 18426259]

Guy, W. ECDEU Assessment Manual for Psychopharmacology. Vol. 76-338. US Department of HEW Publications; Washington, DC: 1976. p. 217-222.

Hare, RD. Without Conscience - The Disturbing World of Psychopaths Among Us. Pocket Books; New York: 1993.

Harvey R, Black DW, Blum N. STEPPS (Systems Training for Emotional Predictability and Problem Solving) in the United Kingdom: a preliminary report. Journal of Contemporary Psychotherapy. 2010; 40:225-232.

Jordan BK, Schlenger WE, Fairbank JA, Caddell JM. Prevalence of psychiatric disorders among incarcerated women. II. Convicted felons entering prison. Archives of General Psychiatry. 1996; 53:513-519. [PubMed: 8639034]

Lenzenweger MF, Lane MC, Loranger AW, Kessler RC. DSM-IV personality disorders in the National Comorbidity Survey Replication. Biological psychiatry. 2007; 62(6):553-564. [PubMed: 17217923]

Lieb K, Zanarini MC, Schmahl C, Linehan MM, Bohus M. Borderline personality disorder. Lancet. 2004; 364(9432):453-461. [PubMed: 15288745]

Linehan MM, Comtois KA, Murray AM, Brown MZ, Gallop RJ, Heard HL, Lindenboim N. Two-year randomized controlled trial and follow-up of dialectical behavior therapy vs therapy by experts for suicidal behaviors and borderline personality disorder. Archives of General Psychiatry. 2006; 63(7):757-766. [PubMed: 16818865]

Mather DB. The role of antisocial personality in alcohol rehabilitation treatment effectiveness. Military Medicine. 1987:516-518. [PubMed: 3120045]

McCann RA, Ball EM, Ivanoff A. DBT with an inpatient forensic population: The CMHIP forensic model. Cognitive and Behavioral Practice. 2000; 7(4):447-456.

National Institute for Health and Clinical Excellence (NICE). Clinical Guideline 77: Antisocial Personality Disorder. Jan. 2009 (www.guidance.nice.uk/CG77)

Pfohl B, Blum N, John DS, McCormick B, Allen J, Black DW. Reliability and validity of the Borderline Evaluation of Severity Over Time (BEST): a self-rated scale to measure severity and change in persons with borderline personality disorder. Journal of Personality Disorders. 2009; 23(3):281-293. [PubMed: 19538082]

Pfohl, B.; Blum, N.; Zimmerman, M. Structured Interview for DSM-IV Personality: SIDP-IV. American Psychiatric Publishing, Inc.; 1997.

SAS Institute Inc.. SAS/STAT: 9.4 Users Guide. SAS Institute, Inc.; Cary, NC: 2011.

Spitzer, RL.; Williams, JBW.; Gibbon, M. Structured Clinical Interview for DSM-IV. New York State Psychiatric Institute, Biometrics Research; New York: 1994.

Verheul R, van den Bosch LM, Koeter MW, De Ridder MA, Stijnen T, Van Den Brink W. Dialectical behaviour therapy for women with borderline personality disorder 12-month, randomised clinical trial in The Netherlands. British Journal of Psychiatry. 2003; 182(2):135-140. [PubMed: 12562741]

Warren JI, Burnette M, South SC, Chauhan P, Bale R, Friend R. Personality disorders and violence among female prison inmates. Journal of the American Academy of Psychiatry and the Law. 2002; 30(4):502-509. [PubMed: 12539904]

Watson D, Clark LA. The PANAS-X: Manual for the positive and negative affect schedule-expanded form. 1999

Weissman MM, Bothwell S. Assessment of social adjustment by patient self-report. Archives of General Psychiatry. 1976; 33:1111-1115. [PubMed: 962494]

Woody GE, McLellan AT, Luborsky L, O'Brien CP. Sociopathy and psychotherapy outcome. Archives of General Psychiatry. 1985; 42(11):1081-1086. [PubMed: 4051686] 
Zanarini MC. Zanarini Rating Scale for Borderline Personality Disorder (ZAN-BPD): A continuous measure of DSM-IC borderline psychopathology. Journal of Personality Disorders. 2003; 17:233242. [PubMed: 12839102]

Zlotnick C. Antisocial personality disorder, affect dysregulation, and childhood abuse among incarcerated women. Journal of Personality Disorders. 1999; 13:90-95. [PubMed: 10228930] 

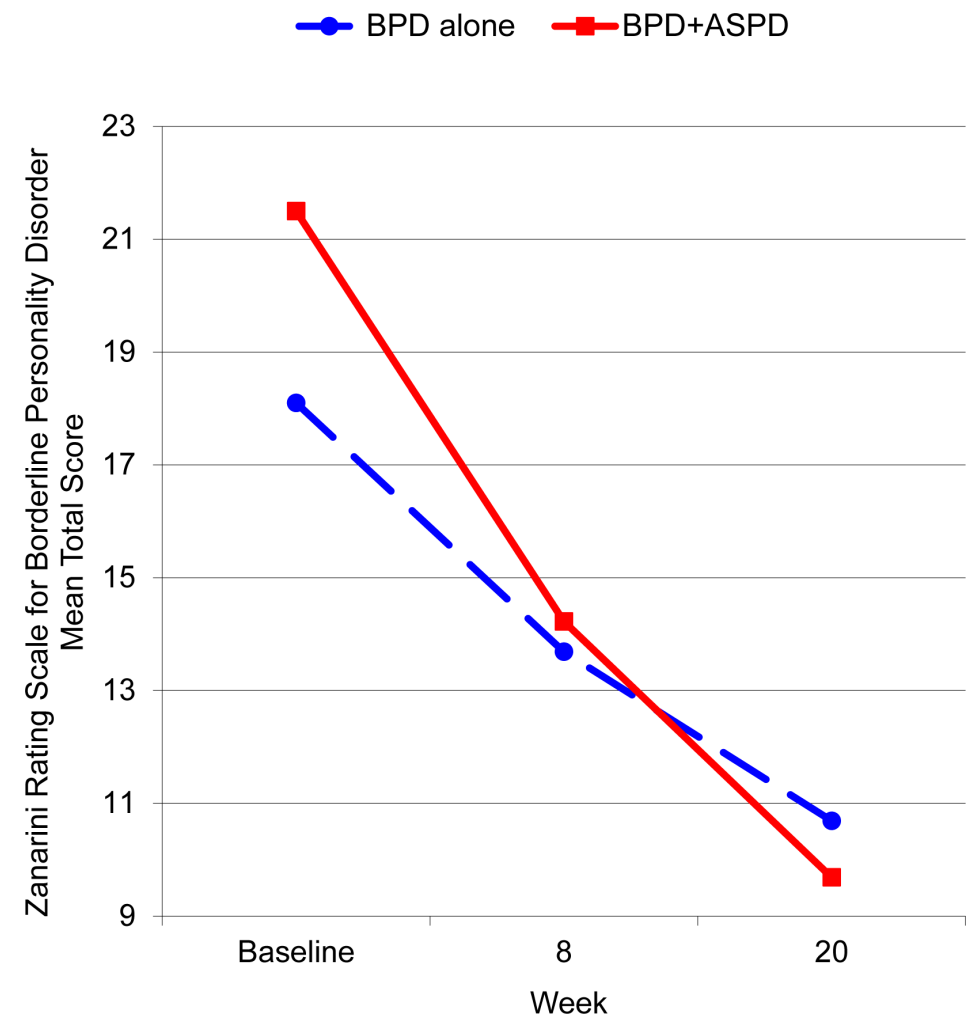

Figure 1.

Improvement in ZAN-BPD Total Score in Subjects Randomized to STEPPS with BPD alone or BPD plus ASPD 

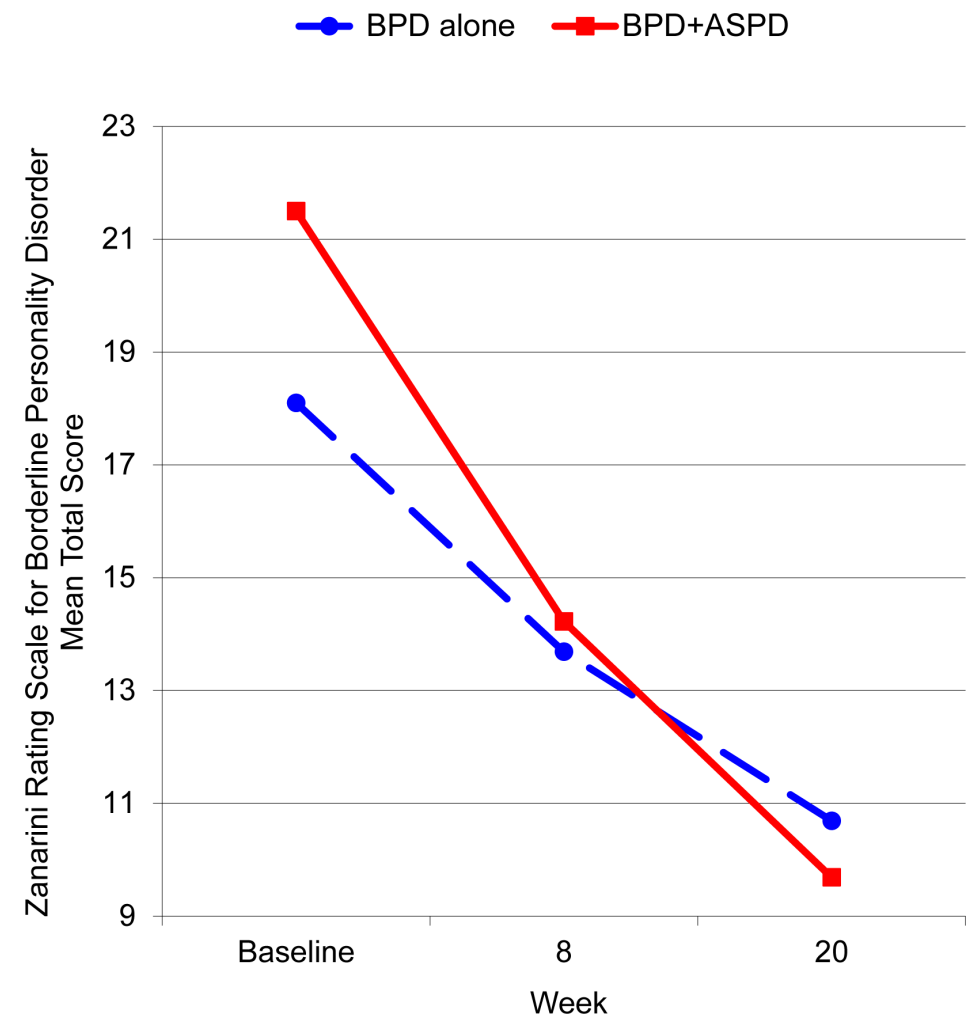

Figure 2.

Improvement in BEST Total Score in Offenders Enrolled in STEPPS with BPD alone or BPD plus ASPD 
Table 1

Social, Demographic, and Clinical Characteristics in 65 Subjects with BPD alone or BPD plus ASPD Randomized to STEPPS

\begin{tabular}{|c|c|c|c|c|c|}
\hline Categorical Variables & BPD alone $(n=49)$ & BPD + ASPD $(n=16)$ & Total $(n=65)$ & $X^{2}, \mathrm{df}$ & P-value \\
\hline Age, years, mean (SD) & $31.7(8.4)$ & $30.5(8.8)$ & $31.4(8.8)$ & $0.7,1$ & 0.406 \\
\hline Sex, No. $(\%)$ & & & & $7.5,1$ & 0.006 \\
\hline Female & $43(88)$ & $9(56)$ & $52(80)$ & & \\
\hline Male & $6(12)$ & $7(44)$ & $13(20)$ & & \\
\hline Race/Ethnicity, No. (\%) & & & & FET & 0.578 \\
\hline Caucasian & $47(96)$ & $15(94)$ & $62(95)$ & & \\
\hline African American & $1(2)$ & $0(0)$ & $1(2)$ & & \\
\hline Other & $1(2)$ & $1(6)$ & $2(3)$ & & \\
\hline Marital Status, No. (\%) & & & & $4.1,2$ & 0.128 \\
\hline Never Married & $17(35)$ & $10(63)$ & $27(43)$ & & \\
\hline Married/Living Together & $17(35)$ & $4(25)$ & $21(32)$ & & \\
\hline Divorced/Separated & $15(31)$ & $2(13)$ & $17(26)$ & & \\
\hline Education, No. (\%) & & & & FET & 0.707 \\
\hline$<$ High School & $1(2)$ & $1(6)$ & $2(3)$ & & \\
\hline High School & $8(16)$ & $2(13)$ & $10(15)$ & & \\
\hline Some College & $27(55)$ & $11(69)$ & $38(58)$ & & \\
\hline College Degree & $8(16)$ & $1(6)$ & $9(14)$ & & \\
\hline Graduate Degree & $5(10)$ & $1(6)$ & $6(9)$ & & \\
\hline Employment, No. (\%) & & & & FET & 0.763 \\
\hline Employed & $19(39)$ & $8(50)$ & $27(42)$ & & \\
\hline Disabled & $14(29)$ & $4(25)$ & $18(27)$ & & \\
\hline Other (e.g., student) & $16(33)$ & $4(25)$ & $20(31)$ & & \\
\hline Past psychiatric hospitalization ${ }^{1}$, No. (\%) & $29(69)$ & $9(69)$ & $38(69)$ & FET & 1.000 \\
\hline Prior suicide attempts, No. (\%) & $33(67)$ & $14(88)$ & $47(72)$ & FET & 0.198 \\
\hline Prior self-harm, No. (\%) & $33(67)$ & $12(75)$ & $45(69)$ & FET & 0.757 \\
\hline Psychotropic medications, mean (SD) & $4.2(2.9)$ & $2.8(2.4)$ & $3.8(2.8)$ & $3.4,1$ & 0.065 \\
\hline Current MDD, No. (\%) & $26(53)$ & $7(44)$ & $33(51)$ & $0.4,1$ & 0.518 \\
\hline \# of SCID disorders, lifetime, mean (SD) & $7.1(3.9)$ & $10.3(5.0)$ & $7.9(4.3)$ & $5.8,1$ & 0.016 \\
\hline \# of SIDP-IV disorders, mean (SD) & $2.7(1.6)$ & $4.5(1.4)$ & $3.1(1.7)$ & $14.3,1$ & $<0.001$ \\
\hline \# of SIDP-IV BPD criteria, mean (SD) & $7.6(1.3)$ & $7.6(1.1)$ & $7.6(1.3)$ & $0.0,1$ & 0.962 \\
\hline
\end{tabular}

FET $=$ Fisher's Exact Test MDD=major depressive disorder

1 Due to missing data on past psychiatric hospitalizations, $n=55$ 
Table 2

Social, Demographic, and Clinical Characteristics in 64 Offenders with BPD alone or BPD plus Enrolled in STEPPS

\begin{tabular}{|c|c|c|c|c|c|}
\hline Categorical Variables & BPD alone $(n=20)$ & $\operatorname{BPD}+\operatorname{ASPD}(n=44)$ & Total $(n=64)$ & $X^{2}, \mathrm{df}$ & P-value \\
\hline Age, years, mean (SD) & $31.6(9.7)$ & $30.6(8.4)$ & $30.9(8.8)$ & $0.0,1$ & 0.873 \\
\hline Sex, No. $(\%)$ & & & & $0.2,1$ & 0.684 \\
\hline Female & $15(75)$ & $35(80)$ & $50(78)$ & & \\
\hline Male & $5(25)$ & $9(20)$ & $14(22)$ & & \\
\hline Race/Ethnicity, No. (\%) & & & & FET & 0.521 \\
\hline Caucasian & $17(85)$ & $40(91)$ & $57(89)$ & & \\
\hline African American & $2(10)$ & $3(7)$ & $5(8)$ & & \\
\hline Other & $1(5)$ & $1(2)$ & $2(3)$ & & \\
\hline Marital Status, No. (\%) & & & & FET & 0.922 \\
\hline Never Married & $8(40)$ & $20(46)$ & $28(44)$ & & \\
\hline Married/Living Together & $5(25)$ & $10(23)$ & $15(23)$ & & \\
\hline Divorced/Separated & $7(35)$ & $13(30)$ & $20(31)$ & & \\
\hline Widowed & $0(0)$ & $1(2)$ & $1(2)$ & & \\
\hline Education, No. (\%) & & & & $0.3,1$ & 0.589 \\
\hline$<$ High School & $6(32)$ & $11(25)$ & $17(27)$ & & \\
\hline High School or more & $13(68)$ & $33(75)$ & $46(73)$ & & \\
\hline Employment, No. (\%) & & & & FET & 0.350 \\
\hline Employed & $8(40)$ & $19(43)$ & $27(42)$ & & \\
\hline Disabled & $7(35)$ & $7(16)$ & $14(22)$ & & \\
\hline Other & $1(5)$ & $3(7)$ & $4(6)$ & & \\
\hline Unemployed & $4(20)$ & $15(34)$ & $19(30)$ & & \\
\hline Past psychiatric hospitalization, No. (\%) & $14(88)$ & $28(70)$ & $42(75)$ & $1.9,1$ & 0.172 \\
\hline Number of medications, mean (SD) & $7.3(7.7)$ & $5.5(3.8)$ & $6.1(5.5)$ & $0.0,1$ & 0.825 \\
\hline \multicolumn{6}{|l|}{ Axis I disorders, No. (\%) } \\
\hline Depressive disorder & $11(69)$ & $34(85)$ & $45(80)$ & $1.9,1$ & 0.167 \\
\hline Bipolar disorder & $6(38)$ & $10(25)$ & $16(29)$ & FET & 0.513 \\
\hline Anxiety disorder & $6(38)$ & $9(23)$ & $15(27)$ & $1.3,1$ & 0.252 \\
\hline Substance use disorder & $5(31)$ & $12(30)$ & $17(30)$ & FET & 1.000 \\
\hline Violent act conviction, No. (\%) & $6(38)$ & $8(21)$ & $14(25)$ & $1.7,1$ & 0.189 \\
\hline
\end{tabular}

FET=Fisher's Exact Test 
Table 3

Outcome Measures in Subjects Randomized to STEPPS with BPD alone or BPD plus ASPD

\begin{tabular}{|l|c|c|c|c|c|c|}
\hline \multirow{2}{*}{ Outcome Measure } & \multicolumn{2}{|c}{ Baseline mean (sd) } & \multicolumn{3}{c}{ Comparing BPD + ASPD to BDP alone } \\
\cline { 5 - 8 } & \multicolumn{2}{|c|}{ Test of slope difference } & \multirow{2}{*}{ ES (se) } \\
\cline { 2 - 7 } & BPD alone & BPD + ASPD & F & df & p & \\
\hline ZAN-BPD Total score & $18.1(5.9)$ & $21.5(8.5)$ & 4.1 & 1,45 & 0.048 & $-0.71(0.35)$ \\
\hline Affective & $7.6(2.7)$ & $8.4(2.9)$ & 1.6 & 1,45 & 0.209 & $-0.53(0.42)$ \\
\hline Cognitive & $3.9(2.1)$ & $4.6(2.5)$ & 0.9 & 1,45 & 0.348 & $-0.31(0.33)$ \\
\hline Impulsivity & $2.7(1.9)$ & $3.9(2.7)$ & 5.0 & 1,45 & 0.031 & $-0.79(0.36)$ \\
\hline Disturbed Relationships & $3.9(1.7)$ & $4.6(2.7)$ & 3.0 & 1,45 & 0.092 & $-0.66(0.39)$ \\
\hline CGI & & & & & & \\
\hline Severity & $5.0(0.7)$ & $5.4(0.7)$ & 0.2 & 1,264 & 0.663 & $-0.16(0.36)$ \\
\hline Improvement & $3.7(0.8)$ & $4.4(1.3)$ & 14.6 & 1,135 & $<0.001$ & $-1.99(0.52)$ \\
\hline Patient Global Self-Rating & $3.6(1.3)$ & $3.8(1.4)$ & 3.1 & 1,126 & 0.080 & $-0.91(0.51)$ \\
\hline GAS & $41.0(11.7)$ & $36.1(8.9)$ & 0.9 & 1,41 & 0.339 & $0.33(0.34)$ \\
\hline BEST & & & & & & \\
\hline Thoughts/Feelings & $23.4(6.3)$ & $22.9(7.1)$ & 0.1 & 1,254 & 0.759 & $-0.13(0.42)$ \\
\hline Negative Behaviors & $9.2(3.1)$ & $9.8(4.0)$ & 0.0 & 1,254 & 0.956 & $0.02(0.37)$ \\
\hline Positive Behaviors & $8.5(2.8)$ & $8.1(2.8)$ & 1.0 & 1,255 & 0.316 & $0.44(0.43)$ \\
\hline Total & $38.9(9.2)$ & $39.6(10.6)$ & 0.2 & 1,254 & 0.679 & $-0.20(0.47)$ \\
\hline PANAS & & & & & & \\
\hline Positive Affectivity & $20.8(9.5)$ & $24.3(8.6)$ & 0.0 & 1,249 & 0.949 & $0.02(0.29)$ \\
\hline Negative Affectivity & $29.3(9.2)$ & $27.8(10.2)$ & 0.3 & 1,251 & 0.598 & $-0.17(0.33)$ \\
\hline BDI & $28.1(11.3)$ & $29.7(13.0)$ & 0.8 & 1,252 & 0.363 & $-0.37(0.41)$ \\
\hline BIS & $78.0(12.8)$ & $88.6(8.2)$ & 7.8 & 1,36 & 0.009 & $-0.88(0.32)$ \\
\hline SCL-90-R GSI ${ }^{1}$ & $16.2(6.6)$ & $15.7(9.0)$ & 0.0 & 1,38 & 0.940 & $-0.03(0.34)$ \\
\hline SAS Total ${ }^{1}$ & $2.8(0.5)$ & $2.7(0.6)$ & 0.3 & 1,39 & 0.600 & $-0.20(0.38)$ \\
\hline
\end{tabular}

GAS=Global Assessment Scale; BEST=Borderline Evaluation of Severity Over Time; ZAN-BPD=Zanarini Rating Scale for Borderline Personality Disorder; PANAS=Positive and Negative Affectivity Scale; BDI=Beck Depression Inventory; BIS=Barratt Impulsiveness Scale; SCL-90$\mathrm{R}=$ Symptom Checklist-90-Revised; GSI=Global Severity Index; SAS=Social Adjustment; ES=Effect size estimated as the group difference in week 20 mean improvement divided by the pooled standard deviation at baseline. 
Table 4

Outcome Measures in Offenders Enrolled in STEPPS with BPD alone or BPD plus ASPD

\begin{tabular}{|c|c|c|c|c|c|c|}
\hline \multirow{2}{*}{ Outcome Measure } & \multicolumn{2}{|c|}{ Baseline mean (sd) } & \multicolumn{3}{c|}{ Comparing BPD + ASPD to BDP alone } \\
\cline { 4 - 7 } & & \multicolumn{2}{|c|}{ Test of slope difference } & \multirow{2}{*}{ ES (se) } \\
\cline { 2 - 7 } & BPD alone & BPD + ASPD & F & df & p & \\
\hline BEST & & & & & \\
\hline Thoughts/Feelings & $19.0(9.7)$ & $22.0(6.5)$ & 1.8 & 1,154 & 0.186 & $-0.46(0.34)$ \\
\hline Negative Behaviors & $7.4(4.3)$ & $8.7(3.3)$ & 4.8 & 1,154 & 0.030 & $-0.55(0.25)$ \\
\hline Positive Behaviors & $11.0(3.0)$ & $9.7(2.8)$ & 8.5 & 1,154 & 0.004 & $1.22(0.42)$ \\
\hline Total & $30.4(13.4)$ & $35.9(9.7)$ & 4.7 & 1,154 & 0.032 & $-0.74(0.34)$ \\
\hline PANAS & & & & & & \\
\hline Positive Affectivity & $29.0(8.6)$ & $28.6(8.3)$ & 7.5 & 1,147 & 0.007 & $0.89(0.32)$ \\
\hline Negative Affectivity & $25.1(10.3)$ & $28.1(8.3)$ & 0.7 & 1,150 & 0.406 & $-0.29(0.35)$ \\
\hline BDI & $19.1(11.19)$ & $26.9(12.3)$ & 2.4 & 1,156 & 0.125 & $-0.45(0.29)$ \\
\hline
\end{tabular}

BEST=Borderline Evaluation of Severity Over Time; PANAS=Positive and Negative Affectivity Scale; BDI=Beck Depression Inventory; ES=Effect size estimated as the group difference in week 20 mean improvement divided by the pooled standard deviation at baseline. 